\title{
EFFECT OF ARTIFICIAL SALIVA, BIOACTIVE GLASS AND FLUORIDE VARNISH ON MICRO-HARDNESS AND MICRO -SHEAR BOND STRENGTH OF DEMINERALIZED ENAMEL SURFACE
}

\author{
Hebatallah M. Taher* and Mohamed Fouad Haridy **
}

\begin{abstract}
Objectives: the aim of this study was to compare the effect of 3 different remineralizing agents on microhardness and microshear bond strength of demineralized enamel surface.

Materials and methods: A total of 50 teeth were divided into five groups (10 each) that were summarized as follows: Group 1: sound unprepared teeth (base line control); Groups 2: demineralized enamel (negative control). Group 3: demineralized enamel stored in artificial saliva for one month. Group 4: demineralized enamel treated by bioactive glass (sylic powder). Group 5: demineralized enamel treated by fluoride varnish (positive control). Five samples from each group were used to test the micro-hardness and the other five samples were used to microshear bond strength.
\end{abstract}

Results: A statistical significant difference was found in microhardness between the sound enamel group and both of the demineralized enamel and the fluoride varnish test groups ,meanwhile no statistically significant difference was found between sound enamel group and both of the artificial saliva test group and the Sylc powder test group. Also, there was a statistically significant difference in microshear bond strength between sound enamel and each of demineralized enamel, demineralized enamel with artificial saliva, demineralized enamel with Sylc powder and demineralized enamel with Fluoride varnish.

Conclusion: The two remineralizing agents; bioactive glass and artificial saliva are capable of enhancing microhardness and micro shear bond strength of demineralized enamel more effectively than fluoride varnish .

\section{INTRODUCTION}

Demineralization of dental hard tissues is still a growing issue and the main cause for dental caries and dentin hypersensitivity ${ }^{1}$. It occur as a result of low $\mathrm{pH}$ in the oral environment due to the production of acids by cariogenic bacteria. Early enamel demineralization is a reversible process including alternating periods of de-and

\footnotetext{
* Associate Professor of Conservative Dentistry, Cairo University and October University for Modern Science and Art .
}

** Associate Professor of Conservative Dentistry, Cairo University and British University in Egypt. 
remineralization. When the number of episodes of remineralization exceed the number of episodes of demineralization, caries is arrested ${ }^{2}$. Fluorides are powerful effective remineralizing agent, enhance the formation of fluorapatite (FAP) which is less soluble and thus more resistant to low $\mathrm{pH}$ values than hydroxyapatite ${ }^{3-5}$ and also inhibit the metabolic and physiological pathways of microorganisms in the cariogenic biofilm that produce organic acids to demineralize dental tissue ${ }^{6}$. Fluoride varnishes have been found to be as safe for use in children as they are applied to the teeth with small amounts and have $48-72 \mathrm{~h}$ adhesion times on the tooth surfaces $^{7}$. Therefore, there has been a growing demand on the use of fluoride varnishes not only for individual applications but also for communitybased caries prevention programs ${ }^{8}$.

More recently, a bioactive glass has been used in dentistry and it enable biomineralization to occur $^{9-11}$. One of them is formed from calcium sodiumphosphosilicate (CSPS) and given the name Novamin. It is amorphous melt-derived glass compound. This glass has shown guarantee in inducing apatite formation when brought into contact with saliva or any physiological fluid. These apatites form either hydroxyapatites ${ }^{12}$ or fluorapatites ${ }^{13}$. Sylc, which is a therapeutic powder that is composed of $100 \%$ Novamin bioactive glass when exposed to an aqueous environment it undergoes a rapid surface reaction, allowing it to physically adhere to exposed dentin and to occlude tubules. This happened within a short period of time so all Sylc reacts to form hydroxycarbonate apatite (HCA), which is chemically similar to natural tooth mineral ${ }^{14,15,16,17}$. Moreover using Sylc in air abrasion units in cavity preparation and / or prior of using resin- bonding procedure can potentially improve the bonding by reducing demineralization via the known defensive enzymatic process ${ }^{18,19}$. So the target of this study was to investigate the remineralization impact of two remineralizing agents Sylc powder and fluorid varnish in combination with artificial saliva on demeneralized enamel as regards the microhardness and micro-shear bond strengh. The null hypothesis established for this study was that there was a different in microhardness and microshear bond strengh between the demineralized enamel and after remineralization using Sylc powder, fluoride varnish and artificial saliva.

\section{MATERIALS AND METHODS}

\section{Teeth selection}

In this in vitro study, fifty recently extracted sound human molar teeth free from caries, hypoplastic defects, fracture or cracks were collected. Teeth were stored in saline solution containing $0.1 \%$ thymol at $4^{\circ} \mathrm{C}$ until used.

\section{Teeth grouping}

Teeth were divided at random into five groups (10 each) that were summarized as follows: Group 1: sound unprepared teeth (base line control); Groups 2: demineralized enamel ( negative control). Group 3: demineralized enamel stored in artificial saliva for one month. Group 4: demineralized enamel treated by bioactive glass (Sylc powder) as remineralizing agent. Group 5: demineralized enamel treated by fluoride varnish ( positive control). Five samples from each group were used to test the microhardness and the other five samples were used to test microshear bond strength.

\subsection{Specimen preparation:}

Each molar was imbedded in rectangular transparent auto-polymerized acrylic resin block (Acrostone, Egypt). The dimensions of the block were $(2.5 \mathrm{~cm} 2.0 \mathrm{~cm} 1.5 \mathrm{~cm})$. The blocks were prepared using split mold assembly that allow for pouring of six blocks at the same time. Each tooth was embedded in the acrylic while it was in soft dough stage and the tooth was pressed in the acrylic till its flat part of the buccal surface was flushed with the flat surface of the mold. After acrylic setting the block was removed from the mold and checked carefully. 


\section{Demineralization phase of teeth:}

All the specimens except the negative control specimens were demineralized by suspending all the teeth into glass tubes containing $20 \mathrm{ml}$ of demineralizing solution $\left(\mathrm{CaCl}_{2}=2.2 \mathrm{mM}, \mathrm{Na} \mathrm{H}_{2} \mathrm{PO}_{4}\right.$ $=2.2 \mathrm{mM}$, Lactic acid $=0.05 \mathrm{M}$, Fluoride $=0.2 \mathrm{ppm}$, solution was adjusted with $50 \% \mathrm{Na} \mathrm{OH}$ to $4.5 \mathrm{pH}$ ). The specimens were stored for 72 hours, in an incubator at a temperature of $37^{\circ} \mathrm{C}^{20}$.

\section{Remineralization phase}

All the specimens except the negative and positive control specimens were treated according to the assigned groups as follows;

\section{Group 3:}

The demineralized specimens were stored in artificial saliva $\left(1.5 \mathrm{mM} / 1 \mathrm{CaCl}_{2}, 50 \mathrm{mM} / 1 \mathrm{KCl}\right.$, $0.9 \mathrm{mM} / 1 \mathrm{KH}_{2} \mathrm{PO}_{4}$, and adjusted $\left.\mathrm{pH}=7.4\right)$. The specimens were kept for thirty days in an incubator at a temperature of $37^{\circ} \mathrm{C}$ and the artificial saliva was changed every 24 hours $^{21}$.

\section{Group 4:}

The demineralized specimens were treated with Bioactive glass 45S5 Sylc powder (Sylc; Denfotex Research Ltd) with particle size $=38-90 \mu \mathrm{m}^{22} . \mathrm{T}$ his powder is composed of $100 \%$ Novamine bioactive glass ; calcium sodium phosphosilicate). The bioactive glass powder was applied according to the manufacturer instructions, it was applied using NSK Prophymate Neo handpiece with air stream adjusted at 40-46 psi. The distance between the handpiece and the specimens was constant about (3-4mm) with 60-80 degrees on the buccal surfaces. The powder application was for 5-10 seconds per specimen in a circular movement.

\section{Group 5:}

The demineralized specimens were treated with fluoride varnish (Bifluorid 10 by VOCO). It is a rapid- drying suspension of equal amounts of sodium fluoride and calcium fluoride. Thin coat was applied on the tooth surface and left for 10-20 seconds then air dried. The single dose form was used, to standardize the amount of fluoride varnish used per specimen.

\section{Microhardness Testing}

The microhardness measurements were performed using a Vickers Microhardness Tester (Model HVS-50, Laizhou Huayin Testing Instrument Co., Ltd. China) with a Vickers diamond indenter and a 20X objective lens. The microhardness measurements were taken at three different points for each sample. The indentations were made approximately $0.5 \mathrm{~mm}$ from each other. Each measurement was carried out by using a 200 -g load for $15 \mathrm{~s}$, oriented perpendicularly to the buccal surface. The diagonal lengths of indentations were measured by built in scaled micrometer and measurements were converted into Vicker's numbers. The values were averaged to produce one hardness value for each sample.

\section{Micro-hardness calculation;}

Micro-hardness was obtained using the following equation:

\section{$H V=1.854 P / d^{2}$}

where,
$\mathbf{H V}$ is Vickers hardness in $\mathrm{Kgf} / \mathrm{mm}^{2}$,
$\mathbf{P}$ is the load in Kgf and
d is the average length of the diagonals in $\mathrm{mm}$

\section{Microshear bond strength testing:}

\section{Bonding procedure}

Etch and rinse approach using the universal adhesive system Single bond universal adhesive (3M ESPE, St Paul, MN, USA) was used according to manufacturer's instructions before resin composite packing. The enamel specimens were etched with phosphoric acid etchant for 30 seconds then rinsed with water for another 30 seconds and finally air-dried for 10 seconds leaving the specimens with 
the chalky white appearance. Two consecutive coats of the adhesive were applied using disposable micro-brushes (Micro-brush-International, Grafton, USA). The first coat was applied with agitation for 20 seconds and left undisturbed for 5 seconds, and then air thinned till no movement of the adhesive is observed then the second coat was applied with the same technique. The adhesive was left uncured to facilitate fixation of the cut microtubes on it before packing of the resin composite into them. The disposable Micro-brushes were replaced after each use.

\section{Resin composite packing for micro-shear bond strength:}

A polyethylene micro-tubes were cut from Tygon ${ }^{\circledR}$ tube (R-3603, Norton Performance Plastic Co., Cleveland, USA) with an internal diameter of $0.8 \mathrm{~mm}$ was cut in $1 \mathrm{~mm}$ measured using RadioShack Electronic Digital Caliper (Part no. 6400192) for standardization. Three micro-tubes were mounted and held in place with a tweezer on the uncured adhesive to restrict the bonding area .

The adhesive coat was then light cured for 10 seconds using a LED light-curing unit (Elipar S10, 3M ESPE, St Paul, MN, USA) operating in standard mode at light intensity $1200 \mathrm{~mW} / \mathrm{cm}^{2}$ according to manufacturer instructions. During light-curing procedure, the light cure tip was held on the top of the mounted micro-cylinder to standardize the distance of curing ( $2 \mathrm{~mm}$ from the adhesive). After curing of the adhesive, the resin composite was packed in the micro-cylinders using endodontic plugger.

The packed resin composite in the cylinders and a plastic matrix strip was placed over the resin composite and gently pressed flat and light-cured for 40 seconds using the same LED light curing unit. Using a sharp scalpel and after one hour of storage at room temperature the polyethylene micro-tubes were peeled away by making two opposite cuts using the tip of scalpel blade number 11 in the micro tube, obtaining composite micro-cylinders of
$0.8 \mathrm{~mm}$ diameter and $1 \mathrm{~mm}$ height bonded to the specimen surface.

The specimens were stored in distilled water for 24 hours prior to micro shear bond strength ( $\mu$-SBS) testing. $\mu$-SBS testing was done using a universal testing machine (Lloyd Instruments Ltd., Fareham UK). A wire of 0.2-mm diameter was looped around the resin composite micro-cylinder, making contact through half its circumference, and was gently held flush against the resin-tooth interface. The resintooth interface, the wire loop and the center of the load-cell were aligned as straight as possible to ensure the correct application of the shear force.

A shearing load with tensile mode of force was applied via materials testing machine at a crosshead speed of $0.5 \mathrm{~mm} / \mathrm{min}$. The relatively slow crosshead speed was selected in order to produce a shearing force that resulted in debonding of the micro cylinder along the substrate-adhesive interface. The load required to debonding was recorded in Newton.

\section{Micro-Shear bond strength calculation:}

- The load at failure was divided by bonding area to express the bond strength in MPa :

$\tau=\mathrm{P} / \pi \mathrm{r}^{2}$

Where; $\tau=$ micro-shear bond strength (in $\mathrm{MPa}$ ).

$\mathrm{P}=$ load at failure (in N). $\pi=3.14$

$\mathrm{r}=$ radius of micro-cylinder (in $\mathrm{mm}$ ) which was checked with a digital caliper before the test.

\section{Statistical Analysis}

The mean and standard deviation values were calculated for each group in each test. Data were explored for normality using Kolmogorov-Smirnov and Shapiro-Wilk tests, data showed parametric (normal) distribution. One-way ANOVA followed by Tukey post hoc test was used to compare between more than two groups for non-related samples. The significance level was set at $\mathrm{P} \leq 0.05$. Statistical analysis was performed with $\quad$ IBM ${ }^{\circledR} \quad$ SPSS $®$ Statistics Version 20 for Windows. 


\section{RESULTS}

\section{Micro hardness results:}

Table 1 and figure 1 demonstrated the correlation between micro hardness results ( Mean \pm SD and level of significance) for all groups. They showed that the highest mean value was found in sound enamel test group, followed by the test group stored in artificial saliva, then in test group treated with Sylc powder and finally ,the test group treated with fluoride varnish, while the lowest mean value was found in the demineralized enamel (negative control).

A statistically significant difference was found between the sound enamel group and both of the demineralized enamel and the fluoride varnish test groups where $(p<0.001)$, meanwhile no statistically significant difference was found between sound enamel group and both of the artificial saliva test group and the Sylc powder test group where $(\mathrm{p}=1)$ and $(\mathrm{p}=0.193)$ respectively. Also, a statistically significant difference was found between the demineralized enamel group and each of artificial saliva test group, Sylc powder test group and fluoride varnish group where $(p<0.001)$.

On the other hand there was no statistically significant difference found between the artificial sa- liva and Sylc powder test groups where $(\mathrm{p}=0.172)$, meanwhile a statistically significant difference was found between artificial saliva and fluoride varnish groups where $(p<0.001)$. Also a statistically significant difference was found between Sylc powder and fluoride varnish groups where $(p<0.001)$ as well.

TABLE (1): The mean, standard deviation (SD) of micro hardness in different groups.

\begin{tabular}{|l|c|c|}
\hline \multirow{2}{*}{\multicolumn{1}{|c|}{ Variables }} & \multicolumn{2}{c|}{ Microhardness } \\
\cline { 2 - 3 } & Mean & SD \\
\hline Sound enamel & $283.28^{\text {a }}$ & 17.59 \\
\hline Demineralized enamel & $160.49^{\mathrm{c}}$ & 7.84 \\
\hline $\begin{array}{l}\text { Demineralized enamel with } \\
\text { artificial saliva }\end{array}$ & $282.71^{\text {a }}$ & 12.44 \\
\hline $\begin{array}{l}\text { Demineralized enamel with Sylc } \\
\text { powder }\end{array}$ & $271.65^{\text {a }}$ & 9.22 \\
\hline $\begin{array}{l}\text { Demineralized enamel with } \\
\text { Fluoride varnish }\end{array}$ & $248.73^{\mathrm{b}}$ & 19.55 \\
\hline p-value & $<0.001^{*}$ \\
\hline
\end{tabular}

Means with different letters in the same column states a statistical significance difference. $*$; significant $(p<0.05)$ ns; non-significant ( $p>0.05)$

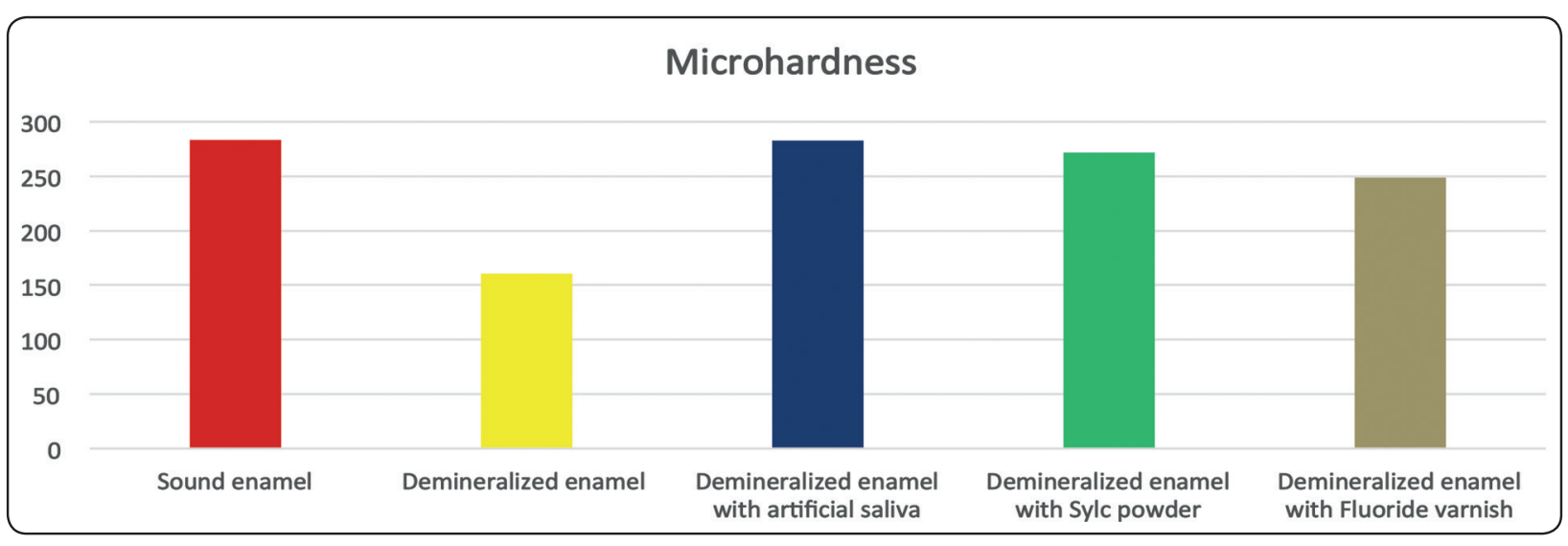

Fig. (1): Bar chart representing micro hardness for different 5 groups 


\section{Shear bond strength results:}

Table 2 and figure 2 demonstrate the correlation between microshear bond strengh results ( Mean $\pm \mathrm{SD}$ and level of significance) for all groups. The highest mean value was found in (Sound enamel) followed by (Demineralized enamel with artificial saliva), (Demineralized enamel with Sylc powder) and (Demineralized enamel with Fluoride varnish), while the lowest mean value was found in (Demineralized enamel). It was found that there was a statistically significant difference between (Sound enamel) and each of (Demineralized enamel), (Demineralized enamel with artificial saliva), (Demineralized enamel with Sylc powder) and (Demineralized enamel with Fluoride varnish) where $\quad(p<0.001), \quad(p=0.014), \quad(p=0.003) \quad$ and $(\mathrm{p}<0.001)$ respectively. On the other hand there was no statistically significant difference between (Demineralized enamel with artificial saliva) and (Demineralized enamel with Sylc powder) where $(\mathrm{p}=0.983)$, while a statistically significant difference was found between (Demineralized enamel with artificial saliva) and (Demineralized enamel with Fluoride varnish) where $(p=0.003)$. Also there was a statistically significant difference between (Demineralized enamel with Sylc powder) and (Demineralized enamel with Fluoride varnish) where $(p=0.014)$ as well.

TABLE (2) The mean, standard deviation (SD) of shear bond strength in different groups.

\begin{tabular}{|l|c|c|}
\hline \multirow{2}{*}{\multicolumn{1}{|c|}{ Variables }} & \multicolumn{2}{c|}{ Shear bond strength } \\
\cline { 2 - 4 } & Mean & SD \\
\hline Sound enamel & $23.53^{\mathrm{a}}$ & 1.56 \\
\hline Demineralized enamel & $12.00^{\mathrm{d}}$ & 1.77 \\
\hline $\begin{array}{l}\text { Demineralized enamel with } \\
\text { artificial saliva }\end{array}$ & $21.52^{\mathrm{b}}$ & 1.15 \\
\hline $\begin{array}{l}\text { Demineralized enamel with Sylc } \\
\text { powder }\end{array}$ & $21.18^{\mathrm{b}}$ & 1.17 \\
\hline $\begin{array}{l}\text { Demineralized enamel with } \\
\text { Fluoride varnish }\end{array}$ & $19.08^{\mathrm{c}}$ & 1.45 \\
\hline p-value & \multicolumn{2}{|c|}{$<\mathbf{0 . 0 0 1 *}$} \\
\hline
\end{tabular}

Means with different letters in the same column states a statistical significance

difference. *; significant $(p<0.05) n s ;$ non-significant $(p>0.05)$

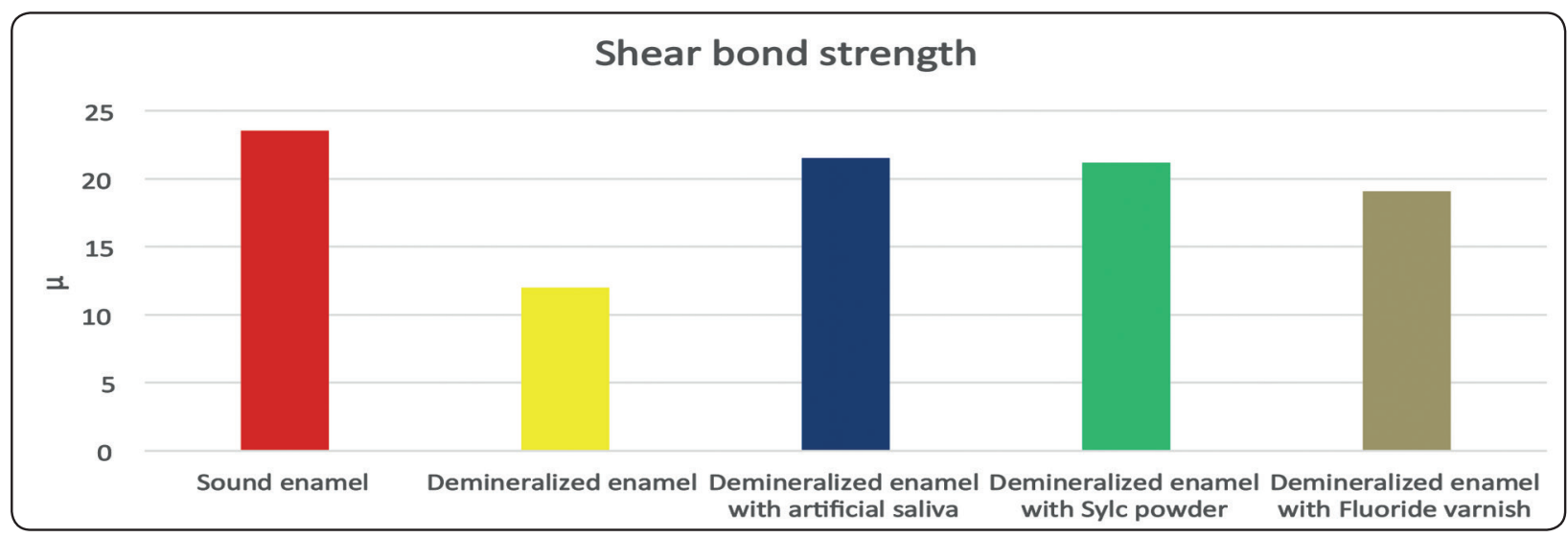

Fig. (2): Bar chart representing shear bond strength for different groups 


\section{DISCUSSION}

Demineralization and remineralization have a vital impact on the hardness and strength of tooth enamel. The battle to keep teeth strong and healthy is mainly depending on the ratio between demineralization and remineralization. During demineralization the enamel crystal, which consists of carbonated apatite, is dissolved by organic acids (lactic and acetic) that are formed by the cellular action of plaque bacteria in the presence of dietary carbohydrates. Remineralization allows the subsequent loss of calcium, phosphate, and fluoride ions to be replaced by fluorapatite crystals ${ }^{23}$. These crystals are more resistant to acid dissolution and are considerably larger than the original crystals, so providing a more favorable and smaller surface to volume ratio. Thus, larger apatite crystals in remineralized enamel are more resistant to enamel breakdown by the resident organic acids. Saliva plays an essential role in neutralizing this acid as it is supersaturated solution of calcium and phosphate. When saliva secretion is stimulated, a rapid rise in $\mathrm{pH}$ to above neutrality occurs enhancing remineralization ${ }^{24,25}$.

Bioactive glasses cover a wide range of clinical applications. It may be used as bone substitutes in periodontology and as dentin desensitizing agents when used for air polishing procedures ${ }^{26-28}$. Bioactive glasses may also be used during restorative procedures as a substitute to alumina in air-cutting/ abrasion units for an alternative noninvasive cavity preparation. It has many advantages, including reduced pain experienced by patients, selective removal of carious dentin and rounded internal cavity angle preparations that minimize stress concentration $^{29}$. NovaMin is calcium sodium phospho-silicate bioactive glass, which release sodium, calcium, phosphate, and soluble silica from its network structure due to its chemical reaction in extracellular body fluids ${ }^{30}$.

The main function of fluoride varnish is the formation of calcium fluoride-like globule, in addition to fluoride uptake into the enamel with fluorapatite formation. The deposited globules act as a fluoride reservoir releasing over time calcium and fluoride ions during demineralization ${ }^{31,32}$. Some in vitro studies suggested that even low salivary fluoride levels can reduce demineralization and enhance remineralization ${ }^{33}$.Caries can be prevented if the level of fluoride exceed $0.03 \mathrm{ppm}$ in the surrounding solutions of the dental hard tissues ${ }^{34-}$ 36. An advantage of varnish is its slow release over time so that repeated doses are not needed. A high concentration at repeated intervals might have toxic effects, although Ekstrand et $\mathrm{al}^{37}$, in their study on fluoride varnish (Duraphat), reported minimal risk of acute toxic reactions.

Micro hardness measurement is suitable for a material having non-homogenous, fine microstructure, or prone to cracking like enamel. Surface micro hardness indentation provides a relatively non-destructive, rapid and simple method in demineralization and remineralization studies. Therefore, in the current study, the micro hardness values for each specimen were measured in three steps; the base line micro hardness, after demineralization and after remineralization. In view of the relationship between mineral content and surface micro-hardness of enamel, the latter can be used as a measure to evaluate the efficacy of different remineralizing materials in stopping the demineralization process. Accordingly, similar to previous research ${ }^{38,39}$ the mean surface microhardness of all samples at baseline and after demineralization was about 283.28 and 160.49 VHN, respectively. In other words, although enamel with primary lesions manifested an even surface, their mineral content, and thus micro-hardness, was lower compared to an intact enamel. On the other hand micro shear bond strength was chosen in this study, as it is considered a dependable parameter for assessing the interfacial bond strength between an adhesive and enamel. Actually, a more-uniform stress distribution is expected to occur, over the small cross-section of micro shear specimens. In addition 
another advantage in the micro-shear method is that multiple specimens can be obtained from one tooth, thus decreasing the number of teeth necessary to obtain a dataset with a sufficient statistical power ${ }^{40}$.

Etch-and-rinse is characterized by an initial etching step, with 32\%-37\% phosphoric acid, followed by a thorough rinsing for complete removal of the smear layer and selective dissolution of the enamel rods. This forms microporosities in the enamel that are penetrated by bonding agents through capillary attraction ${ }^{41}$. Following polymerization, micromechanical interlocking of resin tags within the etched surface gives a strong micromechanical bond $\mathrm{42}^{42}$.

Results of the current study showed that there was a statistically significant difference in micro hardness and micro shear between sound and demineralized enamel, as the later have a low mineral content at the surface layer when compared to sound enamel and also it might influence the hybrid layer formation and chemical interactions with carboxylic and phosphate derivatives of methacrylates; thus showing lower values than for sound enamel tissue ${ }^{43,44,45}$

The artificial saliva test group was showing a statistically significant higher mean value in both microhardness and micro shear bond strength, which is in agreement with Margarita et al $(2017)^{46}$, who expressed that natural saliva and organic components might interfere with the calcium phosphorus deposition (remineralzation capacity). However, it was stated that a complex of calcium phosphate and glycoprotein called salivary precipitin incorporated in the dental plaque, this complex enhanced remineralization. This is due to the high solubility of calcium phosphate in salivary proteins which is eight to ten times higher than calcium phosphate in tooth, leading to reducing demineralization and enhance remineralization. The treatment with natural saliva was only limited to the surface. Moreover, the repair capacity on using synthetic hydroxapatite components is expressed to the depth of the lesion and extended beyond the enamel surface. The current study utilized a solution without organic components, which explains the positive influence on both tested parameters

Also the results show a statistically significant higher mean micro hardness and micro shear values of enamel treated with Sylc powder compared to enamel treated with fluoride varnish. This might be due to the calcium sodium phosphosilicate bioactive glass is gradually substituted by hydrogen ions. As the process continues, a thick layer full of calcium and phosphate precipitates on the tooth surface with an increased $\mathrm{pH}$ of the environment preventing the demineralization process ${ }^{47,48}$. On the other hand when fluoride is applied to demineralized enamel surface, it forms hydroxyapatite fluoride, which has been shown to be more resistant to acidic dissolution than non-fluoridated hydroxyapatite ${ }^{49}$. However, the main effect produced by the fluoride layer on the demineralized enamel surface is the precipitation of globules of calcium fluoride $\left(\mathrm{CaF}_{2}\right)$, known as phosphate-contaminated calcium fluoride. When the enamel surface is etched, calcium fluoride globules or other fluoride composites precipitate onto the enamel surface, and into the interprismatic spaces occupied by water and proteins, reducing the enamel's permeability and, therefore, the movement of fluids ${ }^{50}$. The use of phosphoric acid for etching could increase the formation of calcium fluoride composites and the reduction in permeability would limit penetration by the adhesive thus decrease the micro shear bond strength. Furthermore the current study showed that the enamel stored in artificial saliva has a higher mean micro hardness and microshear values than the demineralized enamel treated with fluoride varnish this ensured that artificial saliva contains chemical compounds such as potassium chloride, calcium chloride, and potassium dihydrogen phosphate, which may improve the enamel remineralization and increase micro hardness ${ }^{51}$. This is in consistent with the study of Gelhard et al.; ${ }^{52}$ and Lussi et al.; ${ }^{53}$. While it was not in agreement with some other studies, including Borges et al.; ${ }^{54}$ in their studies the 
artificial saliva had no effects on enamel hardness, which the difference was related to the difference in artificial saliva formula, immersion time, the type of teeth and different study designs.

Finally, this can explain the benefit of using a remineralizing agents to enhance the microhardness and microshear bond strength of a demineralized enamel rather than elimination and becoming liable to reliable bonding.

\section{CONCLUSION}

Based on in vitro findings, the two remineralizing agents: bioactive glass and artificial saliva are capable of enhancing microhardness and micro shear bond strength of demineralized enamel more effectively than fluoride varnish.

\section{REFERENCE}

1- Neel, E.A.A. et al. Demineralization-remineralization dynamics in teeth and bone. International Journal of Nanomedicine; (2016):11:4743-4763.

2- Pears El \& Moore AJ. Remineralization of softened bovine enamel following treatment of overlying plaque with a mineral-enriching solution. J Dent Res; (1985):64: 416-421

3- Rosin-Grget K, Peros K, Sutej I, Basic K. The cariostatic mechanisms of fluoride. Acta Med Acad; (2013):42(2):179-188.

4- Ten Cate J, Featherstone JDB .Physicochemical aspects of fluoride enamel interactions. In: Fejerskov O, Ekstrand J, Burt BA (eds) Fluoride in dentistry, 2nd edn. Munksgaard, Copenhagen; (1996): pp: 252-269

5- Featherstone JD .The science and practice of caries prevention. J Am Dent Assoc; (2000):131(7):887-899

6- Ten Cate, J. M. Contemporary perspective on the use of fluoride products in caries prevention. Br Dent J; (2013):214: 161-167

7- Fontana M, Gonzalez-Cabezas C, Haider A, Stookey GK Inhibition of secondary caries lesion progression using fluoride varnish. Caries Res; (2013): 36(2):129-135.

8- O'Mullane DM, Baez RJ, Jones S, Lennon MA, Petersen PE, Rugg-Gunn AJ, Whelton H, Whitford GM . Fluo- ride and oral health. Community Dent Health ; (2016) 33(2):69-99

9- Bakry A.S, Marghalani H.Y., Amin O.A Tagami J .The effect of a bioglass paste on enamel exposed to erosive challenge, J. Dent; (2014) 42 :1458-1463.

10- Bakry A.S., Takahashi H, Otsuki M, Tagami,J Evaluation of new treatment for incipient enamel demineralization using 45S5 bioglass, Dent. Mater; (2014) 30: 314-320.

11- Mehta, A.B, Kumari, V, Jose, R, Izadikhah, V. Remineralization potential of bioactive glass and casein phosphopeptide-amorphous calcium phosphate on initial carious lesion: an in-vitro pH-cycling study, J Conserv. Dent; (2014):17:3-7.

12- Hench LL, Bioceramics: from concept to clinic, J. Am. Ceram. Soc; (1991):74:1487-1510.

13- Brauer, D.S., Karpukhina,N, Law,R.V, Hill , R.G, Structure of fluoride-containing bioactive glasses, J. Mater. Chem; (2009):19: 5629-5636.

14- Earl JS1, Leary RK, Muller KH, Langford RM, Greenspan DC. Physical and chemical characterization of dentin surface following treatment with NovaMin technology. J Clin Dent.; (2011):22(3):62-7.

15- Vahid Golpayegani M1, Sohrabi A, Biria M, Ansari G. Remineralization Effect of Topical NovaMin Versus Sodium Fluoride $(1.1 \%)$ on Caries-Like Lesions in Permanent Teeth. J Dent (Tehran). 2012 Winter;9(1):68-75. Epub 2012 Mar 31.

16-. Burwell AK, Litkowski LJ, Greenspan DC. Calcium sodium phosphosilicate (NovaMin): remineralization potential Adv Dent Res.; (2009):21(1):35-9.

17 - Mehta AB, Kumari V, Jose R, Izadikhah V. Remineralization potential of bioactive glass and casein phosphopeptide-amorphous calcium phosphate on initial carious lesion: An in-vitro pH-cycling study. J Conserv Dent. Jan; (2014):17(1):3-7

18- Mazzoni, A., L. Tjaderhane, V. Checchi, R. Di Lenarda, T. Salo, F. R. Tay, D. H. Pashley, and L. Breschi. "Role of Dentin MMPs in Caries Progression and Bond Stability." Journal of Dental Research ;(2014):94.2: 241-51.

19- Comisi, J.C., "The 'Reservoir Restorative' Revolution", Dentistry Today, Volume 35 No.7 Page 126

20- Lata, S., Varghese, N. O., \& Varughese, J. M. Remineralization potential of fluoride and amorphous calcium 
phosphate-casein phospho peptide on enamel lesions: An in vitro comparative evaluation. Journal of conservative dentistry: JCD; (2010): 13(1), 42.)

21- Wang, Z., Jiang, T., Sauro, S., Wang, Y., Thompson, I., Watson, T. F., \& Haapasalo, M. (b) Dentine remineralization induced by two bioactive glasses developed for air abrasion purposes. Journal of dentistry; (2011):39(11): 746756.)

22- Ayam A. Taha, Robert G. Hill , Padhraig S. Fleming, Mangala P. Patel. Development of a novel bioactive glass for air-abrasion to selectively remove orthodontic adhesives Clinical oral investigations ; ( 2017) June;

23- Margeas R. Remineralization with a unique delivery system. Inside Dentistry, May 2006; p.863.

24- Cummins D. The development and validation of a new technology, based upon $1.5 \%$ arginine, an insoluble calcium compound and fluoride, for everyday use in the prevention and treatment of dental caries. J Dent.; (2013):41(2):S1S11.

26- Kleinberg I. A new saliva-based anti-caries composition. Dent Today.(1999)

27- Sauro S, Watson TF, \& Thompson I Dentine desensitization induced by prophylactic and air-polishing procedures: an in vitro dentine permeability and confocal microscopy study Journal of Dentistry ; (2010):38(5): 411-422.

28-. Pashley DH \& Depew DD .Effects of smear layer, copalite and oxalate on microleakage Operative Dentistry; (1986):11(3): 95-102.

29- Hench LL \& Andersson O * Bioactive glasses. In: Hench LL, Wilson J (eds) Introduction to Bioceramics World Scientific, Singapore ; (1993) 45-47.

30- Paolinelis G, Banerjee A, \& Watson TF An in vitro investigation of the effect and retention of bioactive glass airabrasive on sound and carious dentine Journal of Dentistry; (2008):36(3): 214-218.

31- Burwell AK, Litkowski LJ, Greenspan DC. Calcium sodium phosphosilicate (NovaMin $®)$ : remineralization potential. Adv. Dent. Res. 2009 . 21(1):35-39.

32- Conway-McPherson B. Innovation in enamel therapy: The role of fluoride and ACP. ADA CERP: Innovatns_Enamel_ Therapy.pdf Accessed December 14, (2017) .

33-. Carey CM. Focus on fluorides: Update on the use of fluoride for the prevention of dental caries. J Evid Based Dent Prac. (2014): (Suppl. 14):95-102
34- Ten Cate JM, Duijsters PP. Influence of fluoride in solution on tooth mineralization. II Microradiographic data. Caries Res.; (1989):17:513-519

35- Featherstone JD. Prevention and reversal of dental caries: Role of low level fluoride. Community Dent Oral Epidemiol. ;(1999):27:31-40.

36-. Leverett DH, Featherstone JD, Proskin HM, et al. Caries risk assessment by a cross-sectional discrimination model. J Dent Res. ;(1993):72:529-537.

37-. Leverett DH, Proskin HM, Featherstone JD, et al. Caries risk assessment by a cross-sectional discrimination model. J Dent Res.;( 1993):72:538-543.

38- Ekstrand J, Koch G, Petersson LG. Plasma fluoride concentration and urinary fluoride excretion in children following application of fluoride containing varnish $\mathrm{Du}$ raphat. Caries Res; (1980):14:185-9.

39- Lata S, Varghese NO, Varughese JM. Remineralization potential of fluoride and amorphous calcium phosphatecasein phosphor peptide on enamel lesions: an in vitro comparative evaluation. J Conserv Dent.; (2010):13:42-6. doi: 10.4103/0972-0707.62634.

40- Jabbarifar SE, Salavati S, Akhavan A, Khosravi K, Tavakoli N, Nilchian F. Effect of fluoridated dentifrices on surface microhardness of enamel of deciduous teeth. Dent Res J. ;(2011):8:113-7.

41- Gwinnett AJ , \& Matsui A A study of enamel adhesives. The physical relationship between enamel and adhesives Archives of Oral Biology (1967) 12(12) 1615-1619.

42- De Munck J, Van Meerbeek B, Yoshida Y, Inoue S, Vargas M, Suzuki K, Lambrechts P, \& Vanherle GFour-year water degradation of total-etch adhesives bonded to dentin Journal of Dental Research (2003) 82(2) 136-140.

43- Armstrong S, Geraldeli S, Maia R, Raposo LHA, Soares CJ, Yamagawa J. Adhesion to tooth structure: a critical review of "micro" bond strength test methods. Dent Mater ;(2010):26:50-62.

44- Koulourides T, Feagin F, Pigman W. Remineralization of dental enamel by saliva in vitro. Ann NY Acad Sci 1965;131:751-7.

45- Evaluation of the Shear Bond Strength of Nanocomposite on Carious and Sound Deciduous Dentin Seema Deshmukh and B Nandlal Int J Clin Pediatr Dent. 2012 Jan-Apr; 5(1): 25-28. 
46- Margarita V.usuga Vacca1, Carolina Torres-Rodriguez2 Edgar Delgado-Mejia3 Evaluation of an experimental remineralizing agent for repairing enamel surfaces Acta Odontol. Latinoam. 2017 Vol. 30 ( 2) 68-75

47- Pulido MT, Wefel JS, Hermandez MM, Denehy GE, Guzman-Armstrong S, Chalmers JM, et al. The inhibitory effect of MI paste, fluoride and a combination of both on the progression of artificial caries-like lesions in enamel. Oper Dent.; (2008 Sep-Oct):33(5):550-5.

48- Zhang Q, Zou J, Yang R, Zhou X. Remineralization effects of casein phosphopeptide-amorphous calcium phosphate crème on artificial early lesions of primary teeth. Int J Paediatr Dent. ;(2011 )Sep;21:(5):374-81.

49- Ten Cate JM, Duijsters PPE. Influence of fluoride in solution on tooth demineralization. I. Chemical data. Caries Res. 1983;17:193-9.

50- Chersoni S, Bertacci A, Pashley DH, Tay FR, Monte- bugnoli L, Prati C. In vivo effects of fluoride on enamel permeability. Clin Oral Investig. 2011;15(4):443-9.

51- Panich M, Poolthong S. The effect of casein phosphopeptide-amorphous calcium phosphate and a cola soft drink on in vitro enamel hardness. The Journal of the American Dental Association.; 2009 )Apr 30:140(4):455-60.

52- Gelhard TB, Fidler V, Vissink A. Remineralization of softened human enamel in mucin-or CMC- containing artificial salivas. Journal of Oral Pathology \& Medicine. ; (1983) Sep 1; 12(5):336-41.

53- Lussi A, Megert B, Eggenberger D, Jäggi T. Impact of different toothpastes on the prevention of erosion. Caries Research.;(2008):42(1):62-7.

54- Borges AB, Yui KC, D’Avila TC, Takahashi CL, Torres CR, Borges AL. Influence of remineralizing gels on bleached enamel microhardness in different time intervals. Operative Dentistry. ;(2010 )Mar; :35(2):180-6. 